CAE Working Paper \#04-19

Another Look at Sticky Prices and Output Persistence

by

Peng-fei Wang

and

Yi Wen

December 2004 


\title{
Another Look at Sticky Prices and Output Persistence
}

\author{
Peng-fei Wang \\ Department of Economics \\ Cornell University
}

\author{
Yi Wen \\ Department of Economics \\ Cornell University
}

(First Version: December 31, 2004)

\begin{abstract}
Price rigidity is the key mechanism for propagating business cycles in traditional Keynesian theory. Yet the New Keynesian literature has failed to show that sticky prices by itself can effectively propagate business cycles in general equilibrium. This situation may be a direct consequence of the notion that money-in-utility (MIU) and cash-in-advance (CIA) are equivalent mechanisms for generating money demand. They are not. We show that price rigidity in fact can (by itself) give rise to a powerful propagation mechanism of the business cycle under CIA constraint in standard New Keynesian general equilibrium models. In particular, we show that reasonable price stickiness can generate highly persistent, hump-shaped movements in output, investment and employment in response to either monetary or non-monetary shocks. Hence, whether or not price rigidity is responsible for output persistence (and the business cycle in general) is not a theoretical question, but an empirical one.
\end{abstract}




\section{Introduction}

Sticky prices are the key mechanism assumed in traditional Keynesian theory for propagating the impact of monetary shocks as well as other aggregate shocks throughout the economy. But how strong is such a propagation mechanism is not clear in the traditional theory. The textbook IS-LM model, for example, argues that aggregate output tends to stay below the potential output level after a monetary contraction only as long as prices remain unchanged. Yet a much more sluggish response of output to monetary shocks is documented by the empirical literature (see, e.g., Sims 1992, Christiano et al. 1995, and Strongin 1995, among many others). Empirical evidence indicates that the deviation of output from its potential trend seems far more persistent than the estimated degree of price stickiness would suggest. To demonstrate this persistent effect of sticky prices in a fully-specified new Keynesian dynamic-general-equilibrium model has also proven to be difficult, as recently stressed by Chari, Kehoe and McGrattan (CKM 2000). CKM show that empirically plausible degree of price rigidity generates only a modest degree of output persistence in responding to monetary shocks, far from enough to account for the estimated output persistence in the U.S. economy. The usefulness of the sticky price assumption, one of the corner stones in traditional Keynesian theory, is thus under a serious challenge. ${ }^{1}$

The persistence problem raised by CKM (2000) along with others has led researchers to explore other types of rigidities or economic forces, in conjunction with sticky prices, to explain the persistent effects of monetary shocks. For example, Christiano, Eichenbaum, Evans (2003) obtain more persistent output responses to monetary shock by combining both sticky prices and sticky wages on the nominal side, aided by habit formation, adjustment costs, limited participation in money market and variable capital utilization on the real side. Dotsey and King (2001) show that output persistence can be improved by features such as a more important role for produced inputs, variable capacity utilization, and labor supply variability through changes in employment. These elements together can reduce the elasticity of marginal cost with respect to output, improving the persistence of output. Bergin and Feenstra (2000) emphasize interactions between input-output production structures and translog preferences to improve output persistence under sticky prices. Similar results based on production chains can also be found in the work of Huang and Liu (2001). Other researchers such as Mankiw and Reis (2002), Woodford (2001), Erceg and Levin (2001) have emphasized the important

\footnotetext{
${ }^{1}$ For an excellent review of the New Keynesian literature, see Clarida, Gali and Gertler (1999).
} 
role of imperfect-information in helping sticky prices to generate persistent output responses to monetary shocks. ${ }^{2}$

By adding a large number of building blocks, such as real rigidities and complex information structures, into the standard sticky-price model can obviously improve the model's fit in terms of output persistence, but at the expense of simplicity. Often more than one factors are added to entangle with nominal rigidities such that it becomes hard to distinguish exactly which factor is doing what in generating output persistence. In addition, while sticky or imperfect information proves to be effective in giving rise to output persistence, the way they are modeled in the literature often uses partial equilibrium framework. It is shown recently by Keen (2004), for example, that the business cycle implications of sticky information proposed by Mankiw and Reis (2003) may not be robust in general equilibrium models. ${ }^{3}$

This paper takes a step back and asks whether a canonical sticky price model without any additional frictions or rigidities can generate a reasonable degree of output persistence. Putting it another way, this paper asks why sticky prices by itself may fail to provide a strong propagate mechanism for the business cycle. This is an intriguing question because intuitively there is no reason price rigidity would not lead to output persistence, since it could turn i.i.d. shocks into serially correlated movements in the real balance just as effectively as any other types of real rigidities. Real balance in turn could affect aggregate spending and production. Yet despite the exploding literature trying to overcome the persistence problem, what exactly fails the Keynesian sticky price propagation mechanism in general equilibrium models remains unclear. Chari, Kehoe and McGrattan (2000), for example, show the inability of sticky prices in generating output persistence mainly via model simulations. The reasons behind the failure are less clearly presented when capital is included.

We show in this paper that sticky prices can in fact by itself generate highly persistent output movements, contrary to the findings of the existing literature. In particular, we show that empirically plausible price stickiness can generate humpshaped output responses to monetary shocks in a way very similar to the data. Thus,

\footnotetext{
${ }^{2}$ The literature has also explored the implications of sticky wages for output persistence. Models based on staggering wages such as those in Andersen (1998), Erceg (1997), and Huang and Liu (2001) are still not able to generate sufficient degree of real persistence seen in data, though they do alleviate the problem to some extent. Edge (2002) recently establishes conditions under which wage and price staggering are equivalent regarding their effects on output persistence, thus the persistence problem is similar in both sticky-wage and sticky-price models.

Also see Dotsey and King (2004) for the recent new literature on state-dependent pricing in general equilibrium. This literature shows that state-dependent pricing can have dramatically richer propagation mechanisms than time-dependent pricing in generating output and inflation persistence. Kiley (2002) and Benhabib and Farmer (2000) show that externalities can also give rise to output persistence.

${ }^{3}$ Erceg and Levin (2001) is an exception.
} 
sticky prices are certainly a useful assumption in explaining the business cycle as far as theory is concerned. Whether they are responsible for the business cycles in the real world, however, is an empirical question.

The key to understand our finding is to realize that money-in-utility and cashin-advance are not equivalent mechanisms in generating money demand. There are two reasons. First, unless consumption and money enter the utility function as perfect complements, money demand and consumption demand behave very differently under MIU. Second, even if consumption and money enter the utility function as perfect complements, money demand and aggregate demand remain very different under MIU, since aggregate demand includes investment and government spending. Only the CIA constraint makes it possible for money to have important influence on the dynamics of aggregate spending and production. ${ }^{4}$ Hence the reason that the existing literature fails to detect the strong power of sticky prices in propagating shocks lies in its failure to realize that the dynamics of money demand and the dynamics of aggregate spending (output) interact differently depending on how money enters the model. In MIU models, aggregate spending (e.g., $C+I+G+N X)$ are not effectively constrained by money holdings, hence the maximum effect of shocks on aggregate income are always realized in the impact period due to the volatile reactions from investment. This implies monotonic impulse responses. When CIA is imposed on aggregate demand, however, the maximum impact of shocks on aggregate income is subdued and postponed because of the cash-in-advance constraint on total spending. This gives rise to more smoothed output responses to shocks.

There should be little surprise that our findings also contradict a branch of the existing literature that assumes CIA. For example, Yun (1996) studies a CIA constrained sticky price model and finds that money shocks have no persistent effects on output. Ellison and Scott (2000) use the same model and demonstrate that sticky prices not only fail to produce persistent output fluctuations but also generate extremely volatile output at very high frequencies. Both of these papers, however, assume CIA constraint on consumption only. When there is capital in the model, intertemporal substitution between current consumption and future consumption can be achieved through capital accumulation. In this case, imposing CIA constraint only on consumption spending is not effective for generating persistent output, since investment becomes very volatile by serving as the buffer for consumption, and consequently investment will dictate output dynamics. Thus, even if consumption is hump-shaped, output is not. This suggests that investment goods must also be treated as cash goods in order for output (aggregate spending) to display persistence.

\footnotetext{
${ }^{4}$ For example, when both consumption and investment are subject to cash-in-advance constraint.
} 
CIA constraint on investment spending serves essentially as a form of dynamic adjustment costs for investment, which is well known for inducing hump-shaped output persistence. ${ }^{5}$

Notice that under CIA constraint for aggregate spending, sticky prices can lead to hump-shaped output persistence not only under monetary shocks, but also under non-monetary shocks, such as technology shocks and preference shocks. The intuition is exactly the same as above: cash-in-advance postpones the maximum impact of shocks on aggregate demand because agents are forced to intertemporally smooth aggregate spending via real balance accumulation over time. A smoothed aggregate demand thus dictates a smoothed aggregate supply (production). Thus, theoretically speaking, sticky prices have no trouble generating output persistence.

The rest of the paper proceeds as follows. Section 2 demonstrates output persistence under CIA in a highly simplified model without capital. We show in this model that sticky prices can give rise to hump-shaped output responses to money shocks under CIA constraint, but not under MIU when consumption and money are substitutes. Section 3 studies a fully specified general equilibrium model with capital. It is shown that under either monetary or non-monetary shocks, output exhibits hump-shaped persistence as long as investment goods are treated as cash goods. Section 4 concludes the paper with suggestions for future research.

\section{The Basic Model}

\subsection{Households}

A representative household chooses sequences of consumption, $\left\{C_{t}\right\}_{t=0}^{\infty}$, labor supply, $\left\{N_{t}\right\}_{t=0}^{\infty}$, and money demand, $\left\{M_{t}\right\}$, to solve

$$
\max E_{0} \sum_{j=0}^{\infty} \beta^{j}\left[\log C_{t}-a N_{t}\right]
$$

subject to $C_{t}+\frac{M_{t}}{P_{t}} \leq \frac{M_{t-1}+X_{t}}{P_{t}}+w_{t} N_{t}+\Pi_{t}$ and the CIA constraint, $C_{t} \leq \frac{M_{t}}{P_{t}}$; where $X$ is money injection, $P$ is the aggregate goods price in terms of money, $w$ is the real wage, and $\Pi$ is the profit income contributed from firms which the household owns. Notice that, since the current money holdings, $M_{t}$, enter the CIA constraint, there is no inflation tax on consumption. Hump-shaped output persistence remains if the inflation tax effect is allowed. Denoting $\lambda_{1}$ and $\lambda_{2}$ as the Lagrangian multipliers for the budget constraint and the CIA constraint respectively, the first order conditions can be summarized by

\footnotetext{
${ }^{5}$ See, e.g., Wen (1998b).
} 


$$
\begin{gathered}
\frac{1}{C_{t}}=\lambda_{1 t}+\lambda_{2 t} \\
a=\lambda_{1 t} w_{t} \\
\lambda_{1 t}=\beta E_{t} \frac{P_{t}}{P_{t+1}} \lambda_{1 t+1}+\lambda_{2 t} .
\end{gathered}
$$

\subsection{Firms}

The final goods, $Y_{t}$, are produced by a perfectly competitive firm according to the technology, $Y_{t}=\left[\int_{0}^{1} y_{t}(i)^{\frac{\sigma-1}{\sigma}} d i\right]^{\frac{\sigma}{\sigma-1}}$, where $\sigma>1$ measures the elasticity of substitution among the intermediate goods, $y(i)$. Let $p_{t}(i)$ denote the price of intermediate goods $i$, the demand for intermediate goods is given by $y_{t}(i)=\left[\frac{p_{t}(i)}{P_{t}}\right]^{-\sigma} Y_{t}$, and the relationship between final goods price and intermediate goods prices is given by $P_{t}=\left[\int_{0}^{1} p_{t}(i)^{1-\sigma} d i\right]^{\frac{1}{1-\sigma}}$.

Each intermediate good $i$ is produced by a single monopolistically competitive firm according to the following technology, $y_{t}(i)=n_{t}(i)$. Intermediate good firms face perfectly competitive factor markets, and are hence price takers in the factor markets. Profits are distributed to household at the end of each time period. The cost function for firm $i$, can be derived from minimizing $w_{t} n_{t}(i)$ subject to $n_{t}(i) \geq y$. Denoting $\phi_{t}$ as the Lagrangian multiplier, which is also the real marginal cost, the first order condition for cost minimization is given by $w_{t}=\phi_{t}$. Consequently, the real profit in period $t$ is given by $\left(\frac{p_{t}(i)}{P_{t}}-\phi_{t}\right) y_{t}(i)$.

Following Calvo (1983) in assuming that each firm has a probability of 1 $\theta$ to adjust its monopoly price in each period, then a firm's intertemporal profit maximization problem is to choose the optimal price, $p_{t}^{*}$, to maximize

$$
E_{t} \sum_{s=0}^{\infty}(\beta \theta)^{t+s} \Lambda_{t, t+s}\left[\frac{p_{t}^{*}}{P_{t+s}}-\phi_{t+s}\right] y_{t, t+s}(i),
$$

where $\Lambda_{t, t+s} \equiv\left[\frac{C_{t+s}}{C_{t}}\right]^{-1}$ is the ratio of marginal utilities taken as exogenous by the firm; and $y_{t, t+s}$ denotes the firm's output level in period $t+s$ given its optimal price in period $t: y_{t, t+s}(i)=\left[\frac{p_{t}^{*}(i)}{P_{t+s}}\right]^{-\sigma} Y_{t+s}$. The first order condition for optimal monopoly price implies the following pricing rule: 


$$
p_{t}^{*}=\frac{\sigma \sum_{s=0}^{\infty}(\beta \theta)^{t+s} E_{t} \Lambda_{t+s} P_{t+s}^{\sigma} Y_{t+s} \phi_{t+s}}{(\sigma-1) \sum_{s=0}^{\infty}(\beta \theta)^{t+s} E_{t} \Lambda_{t+s} P_{t+s}^{\sigma-1} Y_{t+s}} .
$$

Because all firms that can adjust their prices face the same problem, all monopolist firms will set their prices in the same way as indicated above. The average price of firms that do not adjust prices is simply last period's price level, $P_{t-1}$. Given that only a fraction of $1-\theta$ can adjust their prices in each period, the final good price index can then be written as $P_{t}=\left[\theta P_{t-1}^{1-\sigma}+(1-\theta) P_{t}^{* 1-\sigma}\right]^{\frac{1}{1-\sigma}}$.

\subsection{Equilibrium and Aggregation}

In equilibrium household's first order conditions and firms' profit maximization conditions are satisfied, all markets clear, and the CIA constraint binds. We study symmetric equilibrium only. In a symmetric equilibrium, there are only two types of firms, one that has the chance to adjust price and one that does not. Since all intermediate good firms face the same marginal cost, their labor demand is in the same proportion to their output level, regardless they adjust prices or not. Hence in equilibrium the labor market clearing condition is given by

$$
N_{t}=\int_{0}^{1} n(i) d i=\left\{\theta\left[\frac{p_{t-1}}{P_{t}}\right]^{-\sigma}+(1-\theta)\left[\frac{p_{t}^{*}}{P_{t}}\right]^{-\sigma}\right\} Y_{t},
$$

implying that the aggregate production function is given by:

$$
Y_{t}=\left\{\theta\left[\frac{p_{t-1}}{P_{t}}\right]^{-\sigma}+(1-\theta)\left[\frac{p_{t}^{*}}{P_{t}}\right]^{-\sigma}\right\}^{-1} N_{t} .
$$

If a firm gets to adjust its price, its real profit in period $t$ is given by $\left[\frac{p_{t}^{*}}{P_{t}}\right]^{1-\sigma} Y_{t}-$ $\phi_{t} Y_{t}\left[\frac{p_{t}^{*}}{P_{t}}\right]^{-\sigma}$, and if a firm does not get to adjust its price, its profit is given by $\left[\frac{p_{t-1}}{P_{t}}\right]^{1-\sigma} Y_{t}-\phi_{t} Y_{t}\left[\frac{p_{t-1}}{P_{t}}\right]^{-\sigma}$. The aggregate profit is thus given by

$$
\begin{aligned}
\Pi_{t} & =\frac{\theta p_{t-1}^{1-\sigma}+(1-\theta) p_{t}^{*(1-\sigma)}}{P_{t}^{1-\sigma}} Y_{t}-\left\{\theta\left[\frac{p_{t-1}}{P_{t}}\right]^{-\sigma}+(1-\theta)\left[\frac{p_{t}^{*}}{P_{t}}\right]^{-\sigma}\right\} \phi_{t} Y_{t} \\
& =Y_{t}-w_{t} N_{t}
\end{aligned}
$$


The household aggregate income is then given by $w_{t} n_{t}+\Pi_{t}=Y_{t}$. The final goods market clearing condition is given by $C_{t}=Y_{t}$.

\subsection{Equilibrium Dynamics}

The model is solved by log-linearization around a zero-inflation steady state as in King, Plosser and Rebelo (1988). Using circumflex lower-case letters to denote percentage deviations around steady state, the log-linearized optimal price and the price index are given respectively by $\hat{p}_{t}^{*}=(1-\beta \theta) \sum_{s=0}^{\infty} E_{t}\left(\hat{\phi}_{t+s}+\hat{p}_{t+s}\right)$ and $\hat{p}_{t}=$ $\theta \hat{p}_{t-1}+(1-\theta) \hat{p}_{t}^{*}$, which together imply the New Keynesian Phillips relationship:

$$
\hat{\pi}_{t}=\beta E_{t} \hat{\pi}_{t+1}+\frac{(1-\theta)(1-\beta \theta)}{\theta} \hat{\phi}_{t}
$$

where $\pi$ is the inflation rate, $\hat{\pi}_{t} \equiv \hat{p}_{t}-\hat{p}_{t-1}$.

The log-linearized aggregate production function is given by $\hat{y}_{t}=\hat{n}_{t}$, hence around the steady state the aggregate production function is the same as individual firm's production function. Notice that the CIA constraint can be expressed as $\hat{y}_{t}-\hat{y}_{t-1}=x_{t}-\hat{\pi}_{t}$, where $x \equiv \log \frac{X_{t}}{M_{t-1}}$ denotes the growth rate of nominal money stock. We assume that the monetary authority follows a money growth rule given by $x_{t}=\rho x_{t-1}+\varepsilon_{t}$. The household's first-order conditions are thus reduced to: $(2-\beta) \hat{y}_{t}-2 \hat{\phi}_{t}=-\beta\left(\hat{\pi}_{t+1}+\hat{\phi}_{t+1}\right)$. Substituting out $\pi_{t}$ in this equation and in the New Keynesian Phillips curve using the CIA constraint, the system of equations for solving $\left\{\hat{y}_{t}, \hat{\phi}_{t}\right\}$ are given by:

$$
\begin{gathered}
x_{t}+\hat{y}_{t-1}-(1+\beta) \hat{y}_{t}=\beta E_{t}\left(x_{t+1}-\hat{y}_{t+1}\right)+\frac{(1-\theta)(1-\beta \theta)}{\theta} \hat{\phi}_{t} \\
2 \hat{y}_{t}-2 \hat{\phi}_{t}=\beta \hat{y}_{t+1}-\beta x_{t+1}-\beta \hat{\phi}_{t+1}
\end{gathered}
$$

which can be arranged more compactly as

$$
E_{t}\left(\begin{array}{l}
\hat{y}_{t+1} \\
\hat{y}_{t} \\
\hat{\phi}_{t+1} \\
x_{t+1}
\end{array}\right)=\left(\begin{array}{cccc}
\frac{1+\beta}{\beta} & -\frac{1}{\beta} & \frac{(1-\theta)(1-\beta \theta)}{\beta \theta} & \frac{-1+\rho_{x} \beta}{\beta} \\
1 & 0 & 0 & 0 \\
\frac{-1+\beta}{\beta} & -\frac{1}{\beta} & \frac{1-\beta \theta+\theta+\beta \theta^{2}}{\beta \theta} & -\frac{1}{\beta} \\
0 & 0 & 0 & \rho
\end{array}\right)\left(\begin{array}{l}
\hat{y}_{t} \\
\hat{y}_{t-1} \\
\hat{\phi}_{t} \\
x_{t}
\end{array}\right) .
$$

The eigenvalues of the Jacobian matrix are given by: $\left\{\frac{2}{\beta}, \frac{1}{\beta \theta}, \theta, \rho\right\}$. Note that the first two of the eigenvalues are larger than unit, hence they can be utilized to solve 
the system forward to determine $\left\{\hat{y}_{t}, \hat{\phi}_{t}\right\}$ as functions of the state $\left\{\hat{y}_{t-1}, x_{t}\right\}$. Clearly, the other two smaller roots, $\{\theta, \rho\}$, determine the propagation mechanism of output. The decision rule of output takes the form:

$$
\hat{y}_{t}=\theta \hat{y}_{t-1}+\alpha x_{t}
$$

where $\alpha$ is the elasticity of output with respect to money growth shocks. Clearly, the persistence of output is determined jointly by the degree of price stickiness, $\theta$, and the persistence of shocks. If monetary shocks are $\mathrm{AR}(1)$, for example, then output follows $\operatorname{AR}(2)$ :

$$
\hat{y}_{t}=(\theta+\rho) \hat{y}_{t}-\theta \rho \hat{y}_{t-1}+\alpha \varepsilon_{t},
$$

which implies a hump-shaped impulse response function. Suppose that the average price stickiness is about four quarters in the economy, the probability of not adjusting prices is then $\theta=0.75$. Given that money growth shocks have autocorrelation of $\rho=0.6$, as is commonly assumed in the literature (e.g., CKM 2000), ${ }^{6}$ then the degree of output persistence implied by the model matches the contract multiplier of the U.S. economy estimated by Chari, Kehoe and McGrattan (2000) almost exactly. The maximum impact of a money injection on output is delayed for three quarters after the shock. The simulated impulse responses of output are graphed in Figure 1 (top window).

\footnotetext{
${ }^{6}$ Also see our calibration using post-war data in the next section.
} 
Cash-In-Advance

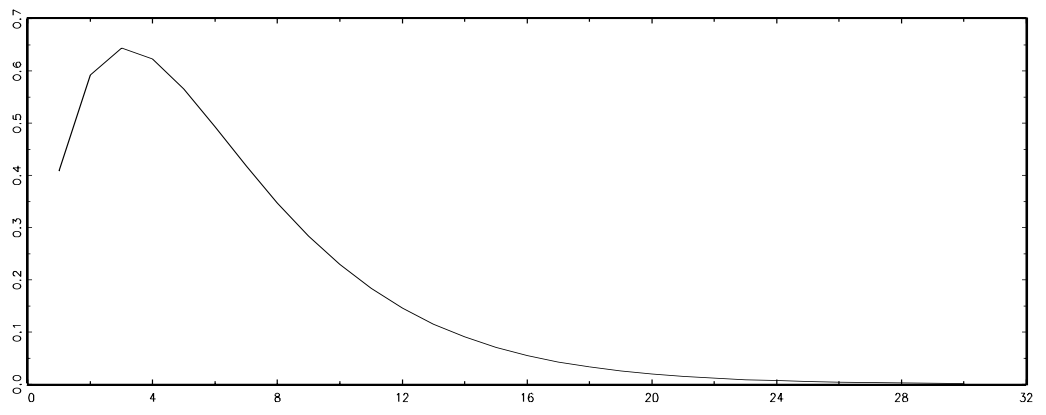

Money-In-Utility

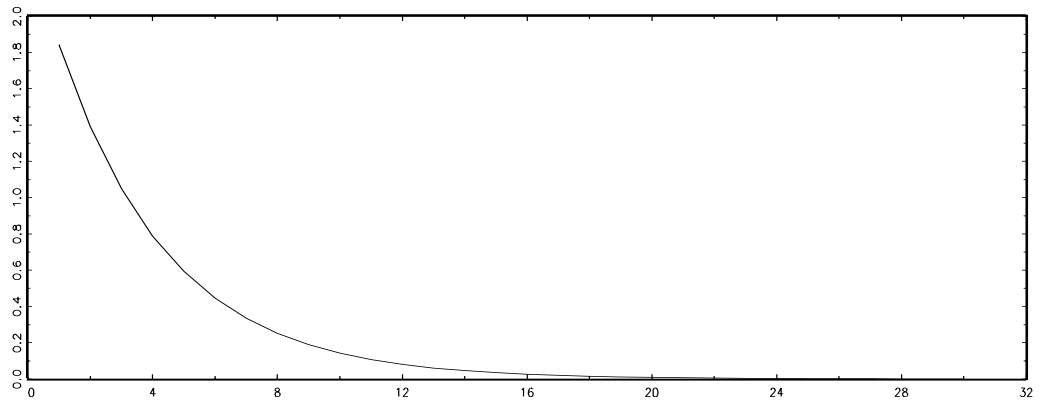

Fig. 1. Impulse Response of Output to Money Shock

When money demand steps from MIU instead, under standard assumptions regarding the elasticity of substitution between consumption and money, no humpshaped output persistence can be generated from the model. To demonstrate, let the household solve:

$$
\max E_{0} \sum_{j=0}^{\infty} \beta^{j}\left[\log C_{t}+\eta \log \frac{M_{t}}{P_{t}}-a N_{t}\right]
$$

subject to $C_{t}+\frac{M_{t}}{P_{t}} \leq \frac{M_{t-1}+X_{t}}{P_{t}}+w_{t} N_{t}+\Pi_{t}$. Let all parameters take the same values as in the previous CIA model. The bottom window in Figure 1 shows that output does not have hump-shaped persistence. Hence, output exhibits hump-shaped persistence under sticky prices only if money can have a strong influence on total spending, such as in the case of CIA. ${ }^{7}$

\footnotetext{
${ }^{7}$ In models without capital, CKM (2000) argue that perfect substitutability between consumption and leisure is crucial for generating output persistence under the Taylor (1980) type of price
} 
The intuition is that cash-in-advance forces agents to intertemporally substitute away current spending for future spending via real balance accumulation, which smooths demand and hence production. In other words, when money has only an utility (income) effect, as is the case in MIU models, it generates its maximum impact on aggregate spending instantaneously, hence not allowing the impact to be built up through time via intertemporal substitution between current spending and future spending. Under CIA constraint, money serves to store real purchasing power under price stickiness. In order to increase spending, agents must increase cash holdings. Thus the initial impact of money injection on demand is subdued, delayed, and transmitted into the future. This effect continues to hold in more general models with capital, as the following section shows. ${ }^{8}$

\section{The Full Model}

\subsection{Households}

The representative household chooses consumption $(C)$, hours $(N)$, capital stock $(K)$, money demand $(M)$, and bond holdings $(B)$ to solves:

$$
\max E_{0} \sum_{t=0}^{\infty} \beta^{t}\left[\Theta \log C_{t}-a \frac{N_{t}^{1+\gamma}}{1+\gamma}\right]
$$

subject to

$$
\begin{gathered}
C_{t}+\left[K_{t+1}-(1-\delta) K_{t}\right]+\frac{M_{t}+B_{t} / R_{t}}{p_{t}}=\frac{M_{t-1}+B_{t-1}+X_{t}}{p_{t}}+r_{t} K_{t}+w_{t} N_{t}+\Pi_{t}-G_{t} \\
C_{t}+K_{t+1}-(1-\delta) K_{t} \leq \frac{M_{t}}{p_{t}}
\end{gathered}
$$

where $r_{t}$ and $w_{t}$ denote real rental rate and real wage rate that prevail in competitive factor markets; $R$ denotes nominal returns to bonds, $\delta$ denotes the depreciation rate of capital. At the end of each period, the household receives wages from hours worked, rental payments from capital lending, and nominal bonds returns as well as

rigidity. Here we find that this requirement is not necessary under the Calvo (1983) type of price rigidity. See Kiley (2002) for discussions regarding the differences between the Taylor type and the Calvo (1983) type of price rigidities.

${ }^{8}$ Technically speaking, the stable root, $\theta$, in the CIA model drives from the real balance due to price stickiness. Hence this root should show up in both the CIA model and the MIU model. However, a crucial difference between the two models is that the real balance dictates aggregate demand only in the CIA model but not in the MIU model. Consequently, lagged output, $y_{t-1}$, shows up as an endogenous state variable in the CIA model but not in the MIU model. 
profits $\Pi_{t}$ from all firms the household owns, and pays a lump sum tax to government in the amount of $G_{t}$. If consumption is the only cash goods, then our model reduces to that of Yun (1996) and Ellison and Scott (2000). ${ }^{9}$

Denoting the Lagrangian multipliers for (3.2) and (3.3) as $\lambda_{1}$ and $\lambda_{2}$ respectively, the first order conditions with respect to $\left\{C_{t}, N_{t}, K_{t+1}, M_{t}, B_{t}\right\}$ can be summarized by

$$
\begin{gathered}
\frac{\Theta_{t}}{C_{t}}=\lambda_{1 t}+\lambda_{2 t} \\
a N_{t}^{\gamma}=\lambda_{1 t} w_{t} \\
\lambda_{1 t}+\lambda_{2 t}=\beta(1-\delta) E_{t}\left(\lambda_{1 t+1}+\lambda_{2 t+1}\right)+\beta E_{t} \lambda_{1 t+1} r_{t+1} \\
\lambda_{1 t}=\beta E_{t} \lambda_{1 t+1} \frac{P_{t}}{P_{t+1}}+\lambda_{2 t} \\
\frac{\lambda_{1 t}}{R_{t}}=\beta E_{t} \lambda_{1 t+1} \frac{P_{t}}{P_{t+1}}
\end{gathered}
$$

\subsection{Firms}

The final good sector is the same as described previously. Hence the demand of intermediate goods is given by $y(i)=\left[\frac{p(i)}{P}\right]^{-\sigma} Y$, and the price index for final goods is given by $P=\left[\int_{0}^{1} p(i)^{1-\sigma} d i\right]^{\frac{1}{1-\sigma}}$. The production technology for intermediate good $i$ is given by $y(i)=A k(i)^{\alpha} n(i)^{1-\alpha}$, Where $0<\alpha<1$ and $A$ denotes aggregate technology shocks to productivity. The cost function of firm $i$ is derived by minimizing $r k(i)+w n(i)$ subject to $A k(i)^{\alpha} n(i)^{1-\alpha} \geq y$. The first order conditions are given by $r=\phi \alpha \frac{y(i)}{k(i)}, w=\phi(1-\alpha) \frac{y(i)}{n(i)}$, where $\phi$ denotes the real marginal cost. Given the production function, the real marginal cost can be written as

$$
\phi_{t}=\frac{1}{A_{t}}\left(\frac{r_{t}}{\alpha}\right)^{\alpha}\left(\frac{w_{t}}{1-\alpha}\right)^{1-\alpha} .
$$

\footnotetext{
${ }^{9}$ CIA constraint on both consumption and investment has been widely used in the literature. For example, see Stockman (1981), Abel (1985), Fuerst (1992), among many others. Stockman (1981) contributes to the literature by showing crucial differences it may make by subjecting investment goods to the CIA constraint. Fuerst (1992) studies the liquidity effect of monetary shocks by subjecting firms to CIA constraint regarding investment finance and wage payments. Carstrom and Fuerst (2001) show that there can be a large difference for monetary policy whether investment is subjected to cash-in-advanced or not. Also see Wang and Yip (1992), and Gong and Zou (2002) for discussions on the implications of subjecting investment to CIA constraint.
} 
Note that, since the total cost equals $\phi_{t} y_{t}(i)$, the marginal cost equals average cost. Let the probability of price adjustment in each period for any intermediate firm be $1-\theta$, a firm's optimal price is again to choose $p^{*}$ to maximize $E_{t} \sum_{s=0}^{\infty}(\beta \theta)^{t+s} \Lambda_{t, t+s}\left[\frac{p_{t}^{*}}{P_{t+s}}-\phi_{t+s}\right]\left[\frac{p_{t}^{*}}{P_{t+s}}\right]^{-\sigma} Y_{t+s}$, which yields the same pricing rule as before:

$$
p_{t}^{*}=\frac{\sigma \sum_{s=0}^{\infty}(\beta \theta)^{t+s} E_{t} \Lambda_{t+s} P_{t+s}^{\sigma} Y_{t+s} \phi_{t+s}}{(\sigma-1) \sum_{s=0}^{\infty}(\beta \theta)^{t+s} E_{t} \Lambda_{t+s} P_{t+s}^{\sigma-1} Y_{t+s}}
$$

\subsection{Aggregation}

At each point of time $t$, firms that have the chance to adjust prices have different factor demand as well as different output and profits from those who do not adjust prices. Aggregation needs to take this into consideration. In a symmetric equilibrium, there are only two types of firms. Utilizing the factor demand functions for each type of firms, the aggregate capital stock and employment can be shown to be:

$$
\begin{array}{r}
K_{t}=\int_{0}^{1} k_{t}(i) d i=\alpha \frac{\phi_{t}}{r_{t}} Y_{t}\left\{\theta\left[\frac{p_{t-1}}{P_{t}}\right]^{-\sigma}+(1-\theta)\left[\frac{p_{t}^{*}}{P_{t}}\right]^{-\sigma}\right\} \\
N_{t}=\int_{0}^{1} n(i) d i=(1-\alpha) \frac{\phi_{t}}{w_{t}} Y_{t}\left\{\theta\left[\frac{p_{t-1}}{P_{t}}\right]^{-\sigma}+(1-\theta)\left[\frac{p_{t}^{*}}{P_{t}}\right]^{-\sigma}\right\} .
\end{array}
$$

Hence the aggregate production function can be expressed as

$$
Y_{t}=A_{t} K_{t}^{\alpha} N_{t}^{1-\alpha} \frac{P_{t}^{-\sigma}}{\theta P_{t-1}^{-\sigma}+(1-\theta) P_{t}^{*-\sigma}}
$$

Notice that near the steady state, the aggregate production function will be independent of prices. The aggregate profit can be shown to be

$$
\begin{aligned}
\Pi_{t} & =\int_{0}^{\theta}\left[\frac{P_{t-1}}{P_{t}}-\phi_{t}\right]\left[\frac{P_{t-1}}{P_{t}}\right]^{-\sigma} Y_{t} d i+\int_{\theta}^{1}\left[\frac{P_{t}^{*}}{P_{t}}-\phi_{t}\right]\left[\frac{P_{t}^{*}}{P_{t}}\right]^{-\sigma} Y_{t} d i \\
& =Y_{t}-w_{t} N_{t}-r_{t} K_{t} .
\end{aligned}
$$

Hence the equilibrium market clearing conditions and resource constraints are given by: 


$$
\begin{gathered}
C_{t}+G_{t}+K_{t+1}-(1-\delta) K_{t}=Y_{t} \\
M_{t}=M_{t-1}+X_{t} \\
B_{t}=B_{t-1}=0 \\
C_{t}+K_{t+1}-(1-\delta) K_{t}=\frac{M_{t}}{P_{t}}
\end{gathered}
$$

The optimal pricing rule in (3.10) in conjunction with the law of motion of the aggregate price index, $P_{t}=\left[\theta P_{t-1}^{1-\sigma}+(1-\theta) P_{t}^{* 1-\sigma}\right]^{\frac{1}{1-\sigma}}$, leads to the same relationship for the dynamics of inflation around the steady state as before: $\hat{\pi}_{t}=$ $\beta E_{t} \hat{\pi}_{t+1}+\frac{(1-\theta)(1-\beta \theta)}{\theta} \hat{\phi}_{t}$, except that the marginal cost function is now different.

\subsection{Steady State and Calibration}

In a zero-inflation steady state, it can be shown that the following relationships hold:

$$
\begin{gathered}
\phi=\frac{\sigma-1}{\sigma} \\
\frac{K}{Y}=\phi \frac{\beta \alpha}{(2-\beta)[1-\beta(1-\delta)]} .
\end{gathered}
$$

Notice that, compared to a standard RBC model in which $\frac{K}{Y}=\frac{\beta \alpha}{1-\beta(1-\delta)}$, there are two distortions on the steady state capital-output ratio in the sticky price model. First, monopolistic competition gives rise to a markup of $\frac{1-\phi}{\phi} \%>0$, which approaches zero only if the elasticity of substitution $\sigma \rightarrow \infty$ (i.e., $\phi \rightarrow 1$ ). A positive markup implies a lower steady state capital-output ratio. Second, due to the fact that money is needed to facilitate transactions, an inflation tax is imposed on investment returns, which lowers the steady state capital-output ration by a factor of $(2-\beta)$. If $\beta=1$, this effects disappears. ${ }^{10}$

The exogenous shocks are assumed to be othorgonal to each other and follow $\operatorname{AR}(1)$ processes in log:

$$
\begin{aligned}
x_{t} & =\rho_{x} x_{t-1}+\varepsilon_{x t} \\
\log A_{t} & =\rho_{A} \log A_{t-1}+\varepsilon_{A t} \\
\log \Theta_{t} & =\rho_{\Theta} \log \Theta_{t-1}+\varepsilon_{\Theta t} \\
\log G_{t} & =\rho_{g} \log G_{t-1}+\varepsilon_{g t}
\end{aligned}
$$

\footnotetext{
${ }^{10}$ See Stockman (1981) for more discussions on this issue.
} 
where $x \equiv \log \frac{X_{t}}{M_{t-1}}$ denotes money growth rate. The model is calibrated at quarterly frequency. We choose the time discounting factor $\beta=0.99$, the rate of capital depreciation $\delta=0.025$, the capital elasticity of output $\alpha=0.3$, the steady-state government spending to output ratio $\frac{G}{Y}=0.2$, the inverse labor supply elasticity $\gamma=0$ (Hansen's indivisible labor), and the elasticity of substitution parameter $\sigma=$ 10 (implying a markup of about 10\%). ${ }^{11}$ We set the shock persistence parameters $\rho_{A}=\rho_{\Theta}=\rho_{g}=0,9$. These parameter values are quite standard in the literature. To calibrate money growth shocks, we estimate an $\mathrm{AR}(1)$ model for the growth rate of monetary base (M0) in the U.S. (1950:1 - 2003:4), and we obtain $\rho_{x}=0.6$ and $\sigma_{\varepsilon x}=0.006$.

\section{Impulse Response and Empirical Evaluation}

The model is solved by log-linearization around the zero-inflation steady-state. The impulse responses of output, consumption, investment and employment to a onestandard-deviation shock to money growth are graphed in Figure 2. Several features are worth noticing in Figure 2. First, a monetary growth shock can cause significant increases in economic activity. On impact, investment increases by 2.6 percent and output increases by 0.56 percent, while consumption increases by only 0.06 percent. The overall standard deviation of investment is about four times that of output, and the overall standard deviation of consumption is about half that of output. These different magnitudes suggest that monetary shocks can explain one of the most prominent business cycle facts emphasized by the real business cycle literature; namely, that consumption is less volatile than output and that investment is more volatile than output.

\footnotetext{
${ }^{11}$ The results are not sensitive to this parameter. For example, similar results obtain even when the markup is zero.
} 

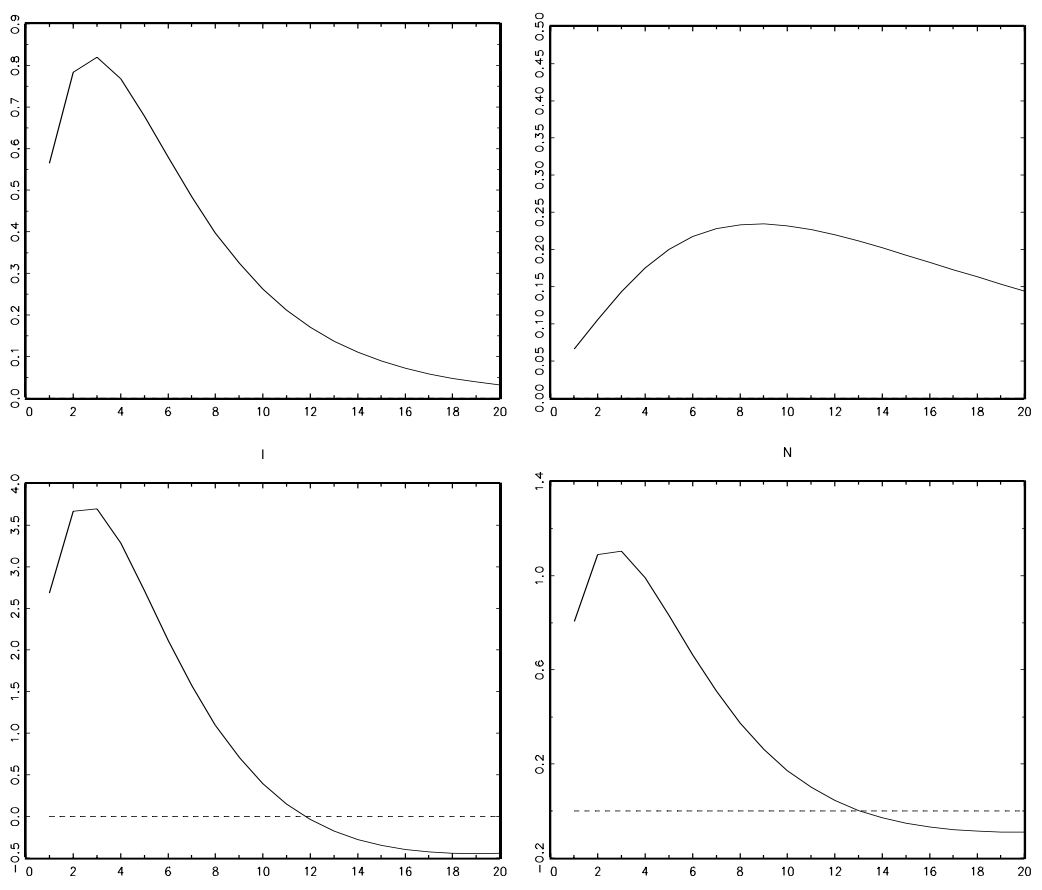

Fig. 2. Impulse Responses to Money Shock

Second and most strikingly, the impulse responses of output $(Y)$, employment $(N)$ and investment $(I)$ are all hump-shaped, with a peak response reached around the third quarter after the shock. This suggests a richer propagation mechanism of the model than a standard RBC model or a sticky-price model with money-in-utility. This richer propagation mechanism induced by sticky prices and the CIA constraint enables the model to match the observed output persistence in the U.S. economy quite well. For example, if we estimate an ARMA process for the logarithm of real GDP of the United States (1950:1 - 2003:4) with a quadratic time trend, then the fitted equation is

$$
\log \left(y_{t}\right)=1.3 \log \left(y_{t-1}\right)-0.37 \log \left(y_{t-1}\right)+v_{t}
$$

where the standard deviation of the residual is $\sigma_{v}=0.0088 .{ }^{12}$ Using this estimated standard deviation to shock the U.S. output, Figure 3 (left window) shows that the

\footnotetext{
${ }^{12}$ CKM (2000) obtain similar estimates.
} 
shape of the impulse response function of the U.S. output looks very much like that implied by the model (where the standard deviation of money shock in the model is $\sigma_{\varepsilon x}=0.006$ ), except that the volatility of the model output is only about one third times that of the data output.

Chari, Kehoe, and McGrattan (2000) propose to measure the persistence of output by its half life. The half-life of output in the model is 9 , while that in the data is 10. Ellision and Scott (2000) show that sticky price models cannot explain the business cycle since they tend to generate too much variations in output at the high frequencies but not enough variations at the business cycle frequencies. Here we show that this conclusion does not hold if investment spending is subject to cashin-advance constraint. The right-hand side window in Figure 3 shows that the power spectrum of output growth in the model matches that in the data quite closely in terms of variance distribution across frequencies. In terms of total variance, however, the model (based on the calibrated money growth shocks) explains only about $16 \%$ of the data. ${ }^{13}$

\footnotetext{
${ }^{13}$ Introducing capacity utilization could improve the model in this regard.
} 

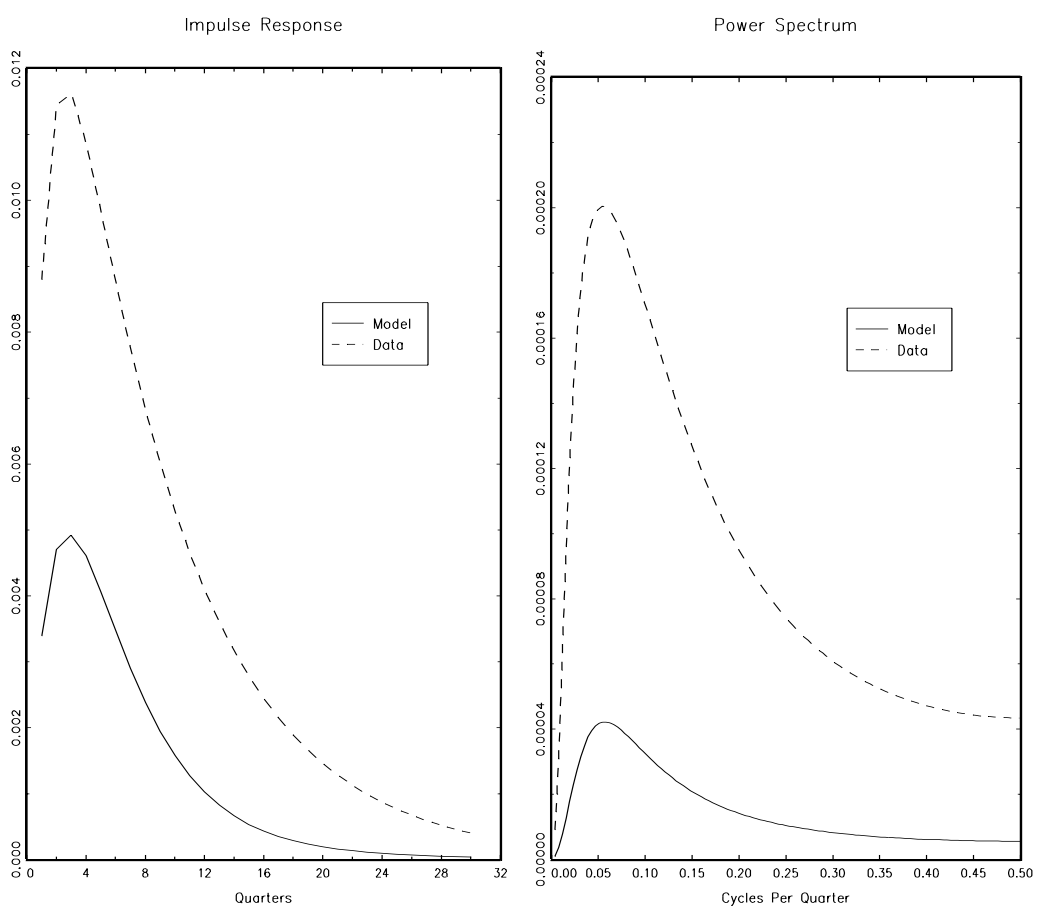

Fig. 3. Output Dynamics of Model and Data

The intuition for the persistent output effect of sticky prices in the full model with capital is similar to that in the basic model without capital. Cash-in-advance acts to smooth aggregate spending across time, since by requiring cash, the maximum impact of shocks on demand (and hence supply) is postponed until enough real balance is accumulated. Thus the CIA constraint serves essentially like an intertemporal form of adjustment cost, which is well know for generating hump-shaped output dynamics. However, if only consumption goods is subject to CIA, output cannot have enough persistence since shocks can immediately impact on investment spending, which will dictates aggregate demand and supply, making output very volatile at the high frequencies (see, e.g., Ellison and Scott 2000). Given that consumption can be smoothed via capital accumulation, it can be shown that CIA constraint on investment goods alone is enough to generate hump-shaped output 
persistence under monetary shocks. ${ }^{14}$

In addition, sticky prices under CIA constraint can also effectively propagate non-monetary shocks. Figure 4 plots the impulse responses of output and employment to one standard deviation technology shocks and preference shocks respectively. It shows that non-monetary shocks can also generate hump-shaped output persistence in the model (windows $\mathrm{A}$ and $\mathrm{C}$ ). This feature of the model is worth emphasizing since it is well known that standard RBC models lack an endogenous propagation mechanism to explain the hump-shaped, trend reverting output response to transitory shocks (Cogley and Nason, 1995, Watson, 1993). Here it is shown that sticky prices can do the job. ${ }^{15}$

One more feature of the model to notice is that employment responds negatively to technology shocks (see Window D in figure 4). Because sticky prices and CIA constraint render aggregate demand rigid in the short run, higher total factor productivity thus induces cost-minimizing firms to lower employment. This negative effect of technology shocks on employment as a result of sticky prices has been empirically documented and explained by Gali (1999). However, in a money-in-utility general equilibrium model, technology shocks generate positive employment even if prices are sticky, since investment can increase to absorb the shocks.

\footnotetext{
${ }^{14}$ Inflation in the model behaves like an $\operatorname{AR}(1)$ process, indicating certain degree of persistence, but not hump-shaped persistence. Hence the model cannot explain the well known fact that inflation lags output. However, its volatility relative to output matches the U.S. data quite well. For the issue of inflation persistence and its relation to output, see Fuhrer and Moor (1995), Ireland (2003), Mankiw and Reis (2003), Wang and Wen (2004), among others.

${ }^{15}$ For other mechanisms that can also generate hump-shaped output dynamics, see Wen (1998a,b,c) and Benhabib and Wen (2004).
} 

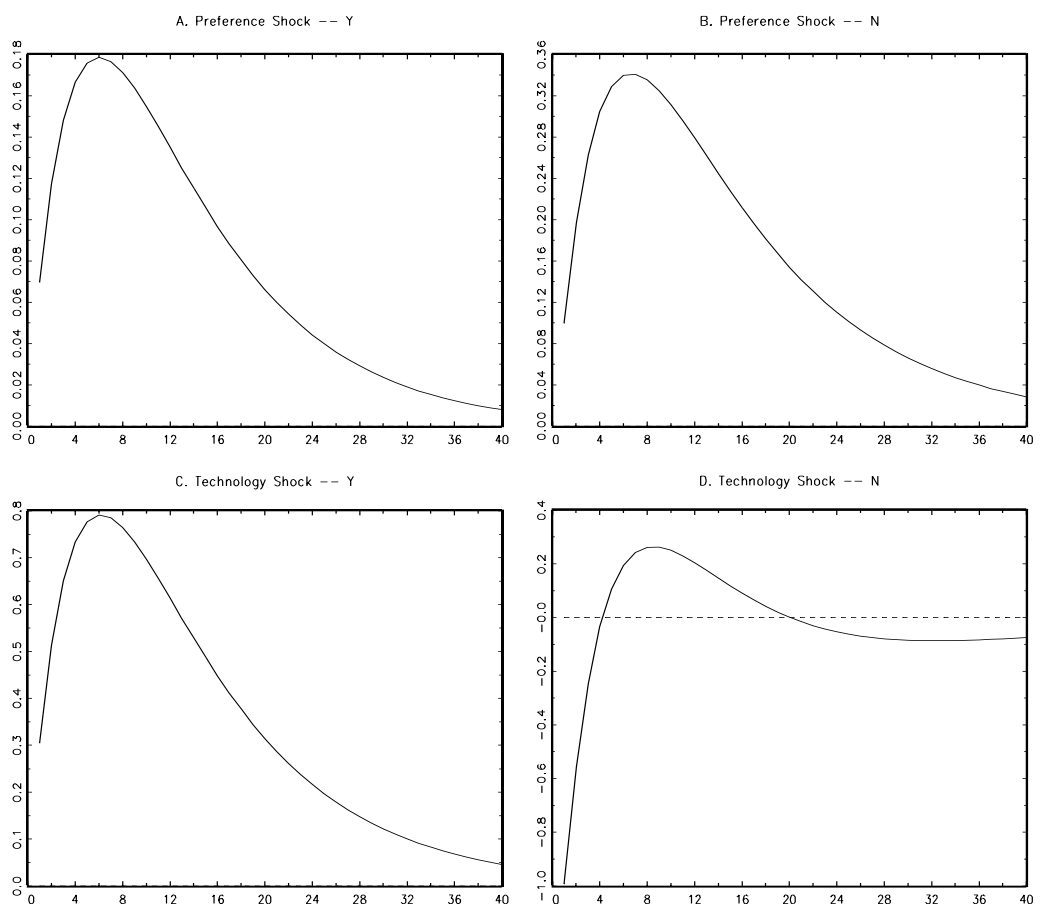

Fig. 4. Effects of Non-Monetary Shocks

\section{Conclusion}

In this paper, we showed that sticky prices can generate strong output persistence if money enters the economy via cash-in-advance constraint instead of via moneyin-utility. In particular, we showed that treating investment goods as cash goods is crucial for sticky price models with capital to generate hump-shaped output persistence. Empirically calibrated monetary shocks seem capable of explaining a broad range of business cycle facts at least as well as technology shocks. Hence whether sticky prices and monetary shocks are responsible for the business cycle is not a theoretical question, but rather an empirical one. Given that multiple mechanisms, such as habit formation in leisure (Wen 1998a), time-to-build (Wen 1998b, which differs from Kydland and Prescott 1982), capacity utilization under increasing returns to scale (Benhabib and Wen 2004, and Wen 1998c), factor hoarding and employment adjustment costs (Wen 2004), among many others, can give rise to hump-shaped output persistence, it would be interesting to empirically test which mechanism 
is the main culprit in propagating the business cycle in the real world. Bills and Klenow (2003), for example, find some empirical evidence against the sticky price propagation mechanism of monetary shocks. Baharad and Eden (2004) find that the staggered price setting assumption is not favored by a micro data. Wang and Wen (2004) show that endogenous monetary policy, rather than sticky prices, are more likely to be responsible for inflation dynamics in the U.S. Also, economic fluctuations in the 1970s and 1980s during the oil crises periods may provide an interesting laboratory to test the monetary theory of the business cycle. Some promising initial researches along this line can be found in Rotemberg and Woodford (1996), Bernanke et al. (1997), Finn (2000), Barsky and Kilian (2001), Hamilton and Herrera (2004), and Aguiar-Conraria and Wen (2004), among others. 


\section{References}

[1] Abel, A., 1985, Dynamic behavior of capital accumulation in a cash-in-advance model, Journal of Monetary Economics 10, 55-71.

[2] Aguiar-Conraria, L. and Y. Wen, 2004, Reconsidering the effects of oil shocks, Working Paper, Cornell University.

[3] Baharad, E. and B. Eden, 2004, Price rigidity and price dispersion: Evidence from micro data, Review of Economic Dynamics 7, 613-641.

[4] Barsky, R. and L. Kilian, 2001, Do we really know that oil caused the great stagflation? A monetary alternative, Macroeconomics Annual, 137-183.

[5] Benhabib, J. and R. Farmer, 2000, The monetary transmission mechanism, Review of Economic Dynamics 3, 523-550.

[6] Benhabib J. and Y. Wen, 2004, Indeterminacy, aggregate demand, and the real business cycle, Journal of Monetary Economics

[7] Bergin, P. and R. Feenstra, 2000, Staggered pricing setting, translog preferences, and endogenous persistence, Journal of Monetary Economics 45, 657680 .

[8] Bernanke, B., M. Gertler and M. Watson, 1997, Systematic monetary policy and the effects of oil price shocks, Brookings Papers on Economic Activity 1, 91-142.

[9] Bills, M. and P. Klenow, 2003, Sticky prices and monetary policy shocks, Federal Reserve Bank of Minneapolis Quarterly Review (Winter 2003).

[10] Calvo, G., 1983, Staggered prices in a utility-maximizing framework, Journal of Monetary Economics 12, 383-389.

[11] Carlstrom, C. and T. Fuerst, 2001, Timing and real indeterminacy in monetary models, Journal of Monetary Economics 47, 285-298.

[12] Chari, V., P. Kehoe and E. McGrattan, 2000, Sticky price models of the business cycle: Can the contract multiplier solve the persistence problem? Econometrica 68, No.5, 1151-1179.

[13] Christiano, L., M. Eichenbaum and C. Evans, 1995, The Effects of monetary policy shocks: some evidence from the Flow of funds, Review of Economics and Statistics 78, 16-34. 
[14] Christiano, L., M. Eichenbaum, and C. Evans, 2003, Nominal rigidities and the dynamic effects of a shock to monetary policy. Working Paper, Northwestern University.

[15] Clarida, R., J. Gali, and M. Gertler, 1999, The science of monetary policy: A New Keynesian perspective, Journal of Economic Literature 37, 1661-1707.

[16] Cogley, T. and Nason, J., 1995, Output dynamics in real-business-cycle models, American Economic Review 85, 492-511.

[17] Cooley, T. and G. Hansen, 1989, The inflation tax in a real business cycle model, American Economic Review 79, 773-748.

[18] Dotsey, M. and King, R. G., 2001, Pricing, production and persistence, NBER Working Paper 8407.

[19] Dotsey, M. and King, R. G., 2004, Implications for state-dependent pricing for dynamic macroeconomic models, Working Paper, Boston University.

[20] Edge, R., 2002, The equivalent of wage and price staggering in monetary business cycle models, Review of Economic Dynamics 5, 559-585.

[21] Ellison, M. and A. Scott, 2000, Sticky prices and volatile output, Journal of Monetary Economics 46, 621-632.

[22] Erceg, C. and A. Levin, 2003, Imperfect credibility and inflation persistence, Journal of Monetary Economics 50, 915-944.

[23] Feenstra, R.C., 1986, Functional equivalence between liquidity costs and the utility of money, Journal of Monetary Economics 17, 271-292.

[24] Finn, M., 2000, Perfect competition and the effects of energy price increases on economic activity, Journal of Money Credit, and Banking, 400-417.

[25] Fuerst, T.S., 1992, Liquidity, loanable funds, and real activity, Journal of Monetary Economics 29, 3-24.

[26] Gali, J., 1999, Technology, employment, and the business cycle: Do technology shocks explain aggregate fluctuations? American Economic Review 89 (March), 249-271.

[27] Gong L. and H. F. Zou, 2001, Money, social status, and capital accumulation in a cash-in-advance model, Journal of Money, Credit and Banking 33, No.2, 284-293. 
[28] Hamilton, J. and A. Herrera, 2004, Oil Shocks and Aggregate Macroeconomic Behavior: The Role of Monetary Policy, Journal of Money, Credit, and Banking, $36,265-286$.

[29] Huang, K. and Z. Liu, 2001, Production chains and general equilibrium aggregate dynamics, Journal of Monetary Economics 48, 437-462.

[30] Huang, K. and Z. Liu, 2002, Staggered price-setting, staggered wage-setting, and business cycle persistence, Journal of Monetary Economics 49, 405-433.

[31] Ireland, P., 2003, Endogenous money or sticky prices? Journal of Monetary Economics 50, 1623-1648.

[32] Keen, B., 2004, Sticky price and sticky information price setting models: What is the difference? Working Paper, Texas Tech University.

[33] Kiley, M., 2002, Partial adjustment and staggered price setting, Journal of Money, Credit, and Banking 34, 283-298.

[34] King, R., C. Plosser and S. Rebelo, 1988, Production, growth and business cycles: I. The basic neoclassical model, Journal of Monetary Economics 21, 195-232.

[35] Kydland, F. and E. Prescott, 1982, Time to build and aggregate fluctuations, Econometrica 50 (6), 1345-1370.

[36] Mankiw, G. and R. Reis, 2002, Sticky information versus sticky prices: A proposal to replace the New Keynesian Phillips curve, Quarterly Journal of Economics 117, 1295-1328.

[37] Rotemberg, J. and Woodford, M., 1996, Imperfect competition and the effects of energy price increases on economic activity, Journal of Money, Credit, and Banking 28, 549-577.

[38] Sims, C., 1992, Interpreting the macroeconomic time series facts: The effects of monetary policy, European Economic Review 36, 975-1000.

[39] Strongin, S., 1995, The identification of monetary policy disturbances: Explaining the liquidity puzzle, Journal of Monetary Economics 35, 463-497.

[40] Stockman, A., 1981, Anticipated inflation and the capital stock in cash-inadvance economy, Journal of Monetary Economics 8, 387-93. 
[41] Taylor, J., (1980), "Aggregate dynamics and staggered contracts", Journal of Political Economy 88, 1-23.

[42] ——, (1999), Staggered price and wage setting in macroeconomics, in: J. B. Taylor and M.Woodford, eds., Handbook of macroeconomics, Vol. 1 (NorthHolland, Amsterdam) ,1009-1050.

[43] Wang, P.F. and Y. Wen, Endogenous money or sticky prices? Comment on monetary non-neutrality and inflation dynamics, Journal of Economic Dynamics and Control (forthcoming).

[44] Wang, P. and C. Yip, 1992, Alternative approaches to money and growth, Journal of Money, Credit, and Banking 24, 553-62.

[45] Watson, M., 1993, Measures of fit for calibrated models, Journal of Political Economy 101, 1011-1041.

[46] Wen, Y., 1998a, Can a real business cycle model pass the Watson test? Journal of Monetary Economics 42, 185-203.

[47] Wen, Y., 1998b, Investment cycles, Journal of Economic Dynamics and Control $22,1139-1165$.

[48] Wen, Y., 1998c, Capacity utilization under increasing returns to scale, Journal of Economic Theory 81, 7-36.

[49] Wen, Y., 2004, What does it take to explain procyclical productivity? Contributions to Macroeconomics 4 (No. 1, Article 5).

[50] Woodford, M., 2001, Imperfet common knowledge and the effects of monetary policy, NBER Working Paper 8673.

[51] Yun, T., 1996, Nominal price rigidity, money supply endogeneity, and business cycles, Journal of Monetary Economics 37, 345-370. 